\title{
Graft-induced Recovery of Inhibitory Avoidance Conditioning in Striatal Lesioned Rats is Related to Choline Acetyltransferase Activity
}

\author{
Ana Luisa Piña, Christopher Edward Ormsby, María Isabel Miranda, Nicolás Jiménez, Ricardo Tapia and \\ Federico Bermúdez-Rattoni
}

Instituto de Fisiología Celular, Universidad Nacional Autónoma de México, Departamento de Neurociencias, México

\section{SUMMARY}

Four groups of male Wistar rats showing disrupted inhibitory avoidance conditioning due to striatal lesions received either striatal or ventral mesencephalic brain grafts. Two additional non-lesioned groups were used as controls. Half of the groups was retrained in an inhibitory avoidance task at fifteen days postgraft and the other half at sixty days postgraft. Those animals receiving striatal grafts significantly improved their ability to acquire the inhibitory avoidance task at fifteen and sixty days postgraft, as opposed to those receiving mesencephalic grafts, which did not show behavioral recovery. Choline acetyltransferase and glutamate decarboxylase activities, as well as dopamine content, were measured in the grafted tissue. Striatal grafts showed levels of choline acetyltransferase activity similar to the control group. Moreover, a positive correlation was found between the choline acetyltransferase activity and the behavioral recovery. In contrast, both glutamate decarboxylase activity and dopamine levels were significantly lower in striatal and in mesencephalic grafts, as compared to the controls. These results show that striatal but not mesencephalic grafts can promote the restoration of the ability to acquire an inhibitory avoidance task even at early stages

Reprint address:

Ana Luisa Piña

c/o Federico Bermúdez-Rattoni

Instituto de Fisiología Celular

Universidad Nacional Autónoma de México

Ap. Postal 70-253

México D.F. 04510, México
(15 days) of the development of the grafts. The results also suggest that acetylcholine plays an important role in behavioral recovery.

\section{KEY WORDS}

striatal grafts, inhibitory avoidance, choline acetyltransferase

Several reports indicate that neural grafts can promote the recovery of lesioned rats from functional deficits $/ 3,5,6 /$. In particular, grafts of striatal fetal tissue implanted into electrolytic or excitotoxic lesioned striatum can reverse many of the functional and behavioral deficits associated with neostriatal damage $/ 4,9,10,24,29 /$. In our laboratory, it has been demonstrated that striatal but not mesencephalic grafts can promote the recovery of inhibitory avoidance conditioning in bilaterally lesioned rats at 60 days post-transplantation, whereas lesioned animals do not show spontaneous recovery $/ 22 /$.

In this report, we assess the effects of striatal grafts on the recovery of the ability to acquire a passive avoidance learning task in striatal lesioned animals at fifteen and sixty days. In addition, we performed biochemical determinations of choline acetyltransferase (ChAT) and glutamate decarboxylase (GAD) activities and dopamine content in the grafted tissue, and correlated them with the behavioral recovery.

One hundred and fifty four male Wistar rats weighing 250-290 g were randomly assigned to one of two groups (control intact rats, $\mathrm{CON}, \mathrm{n}=42$, 
and lesioned group, $\mathrm{n}=112$ ). Large bilateral electrolytic lesions were made under pentobarbital anesthesia $(50 \mathrm{mg} / \mathrm{kg})$ by means of a $1 \mathrm{~min}, 2 \mathrm{~mA}$ cathodic current to encompass the dorsal striatum (stereo-taxic coordinates: $\mathrm{AP}=-0.5, \mathrm{~L}= \pm 3.5, \mathrm{DV}$ $=-5.5$ and -6.5 , from skull level; incisor bar -5.0 $\mathrm{mm})$. Following post-operative recovery (8 days) each animal was trained and tested in a step-through inhibitory avoidance task conducted in a shuttle box $(40 \times 15 \times 20 \mathrm{~cm})$ divided into two compartments by a sliding door. One of the compartments was indirectly illuminated by a $40 \mathrm{~W}$ light bulb. The other compartment was not illuminated and had a metal floor through which a brief electric shock could be delivered. During the acquisition session each animal was placed in the illuminated compartment for $30 \mathrm{sec}$, after which the rat was allowed to enter the dark compartment. When the four paws of the rat were inside the dark compartment, the door was closed and a $0.8 \mathrm{~mA}$ DC footshock was delivered for 3 seconds. The animal was then allowed to escape to the safe (illuminated) compartment. Twenty-four hours later the same procedure was followed except that the footshock was not delivered (test session). For each session, the time (latency) that the rat took to move from the illuminated to the dark compartment was noted. Two more extinction tests were performed at 48 and 72 hours after the acquisition session.

Fifteen days after surgery, the lesioned animals were randomly assigned to 2 subgroups: one group received striatal fetal tissue (ST), and the other received mesencephalic fetal tissue (MS). Fifteen day-old fetuses (crown-rump length 13-15 mm) were removed from the abdominal cavity of anesthetized pregnant rats. The fetal brains were removed, and the striatum and ventral mesencephalon were dissected under a stereoscopic microscope. Blocks of tissue approximately $3 \mathrm{~mm}^{3}$ were injected bilaterally through a $100 \mu \mathrm{l}$ Hamilton microsyringe (internal diameter $0.5 \mathrm{~mm}$ ) into the area where the previous lesion was made. All the groups were then divided into two subgroups, which were retrained for inhibitory avoidance at 15 (ST-15, $\mathrm{n}=31$; MS-15, $\mathrm{n}=21, \mathrm{CON}-15, \mathrm{n}=19$ ) and 60 days post-graft respectively (ST-60, $n=31$; MS-60, $n=29$; CON-60, $n=23$ ).

At the end of the experiment, rats from ST, MS and CON groups were decapitated and the brains were rapidly removed and dissected on ice. Graft tissue was carefully obtained. We clearly identified the grafts through a stereoscopic microscope, the graft tissue being more translucent than the rest of the adult brain tissue. For dopamine determinations (ST-15, $\mathrm{n}=9$; MS-15, $\mathrm{n}=9$; CON-15, $\mathrm{n}=4$; ST$60, n=18 ; M S-60, n=17$; CON-60, $n=13$ ) the tissue was weighed and homogenized on ice in percloric acid containing dihydroxybenzylamine (DHBA). The homogenates were centrifuged, the supernatants were filtered and $20 \mu \mathrm{l}$ were used for HPLC/electrochemical detection (Beckman, System Gold). The measurement of catecholamines was done by the method previously described /27/. Concentrations of standard solutions of dopamine were run in parallel to make the quantitative calculations $/ 27 /$. ChAT $/ 14,17,18 /$ and GAD activities $/ 1,17 /(\mathrm{ST}-15, \mathrm{n}=22 ; \mathrm{MS}-15, \mathrm{n}=12$; CON-15, $\mathrm{n}=15 ; \mathrm{ST}-60, \mathrm{n}=13 ; \mathrm{MS}-60, \mathrm{n}=12$; CON-60, $n=10$ ) were measured in water homogenates of the grafted tissue by radioisotopic techniques previously described in detail, using $\left[{ }^{3} \mathrm{H}\right]$-acetyl-coenzyme-A or $\left[1-{ }^{14} \mathrm{C}\right]$-L-glutamic acid (Amersham, Buckinghamshire, UK) as substrates. Some of the tissue samples that were used for determinations of ChAT activity were also used for measuring GAD activity. Protein was determined using the Folin reagent method /19/.

Nonparametric statistics were applied on latency scores for inhibitory avoidance, since a maximum of 600 s was established in the procedure, making this measure ordinal. A Kruskal-Wallis test was applied for comparisons among groups, and a post hoc twotailed Mann-Whitney U-test for comparisons between groups. For the biochemical measurements, a one-way ANOVA was applied with post hoc Fisher analyses.

For the fifteen day-old grafts, the post-lesion and post-graft results are shown in Figure 1A. The postlesion acquisition sessions showed no significant differences among groups. During the first test trial (post-lesion) there were differences among groups $(p<0.01)$. As expected, the control group showed the highest latency and all the lesioned animals showed significantly lower latencies $(p<0.01)$. The post-graft comparisons for the acquisition day revealed significant differences between groups $(p<0.05)$ for 15 day-old grafts. The statistical analysis of the acquisition at 15 days revealed that 
$1 \mathrm{~A}$
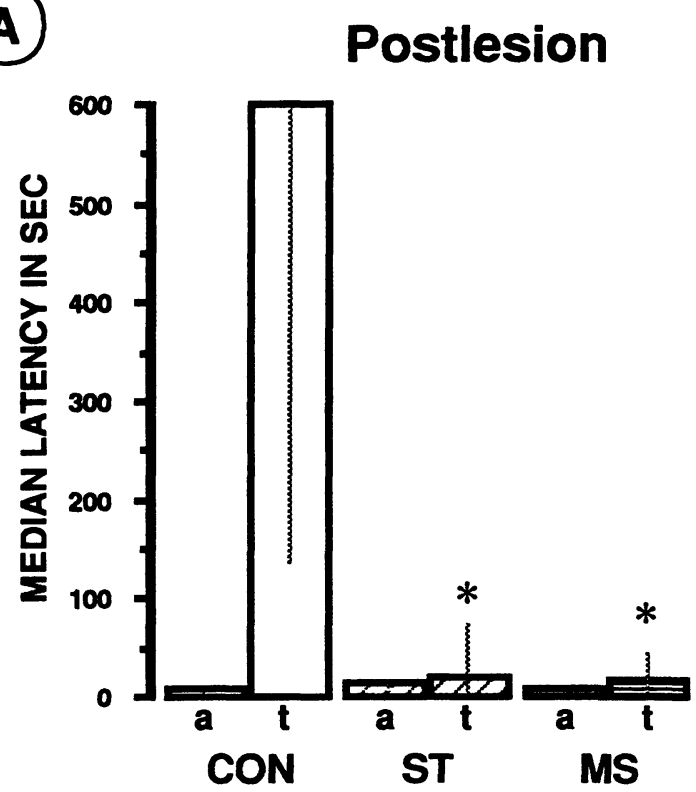

Fifteen day old grafts

Postgraft

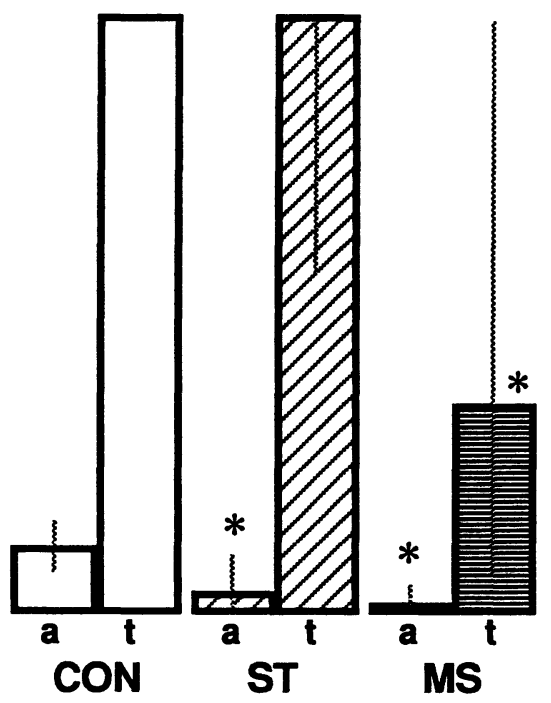

1B

Sixty day old grafts
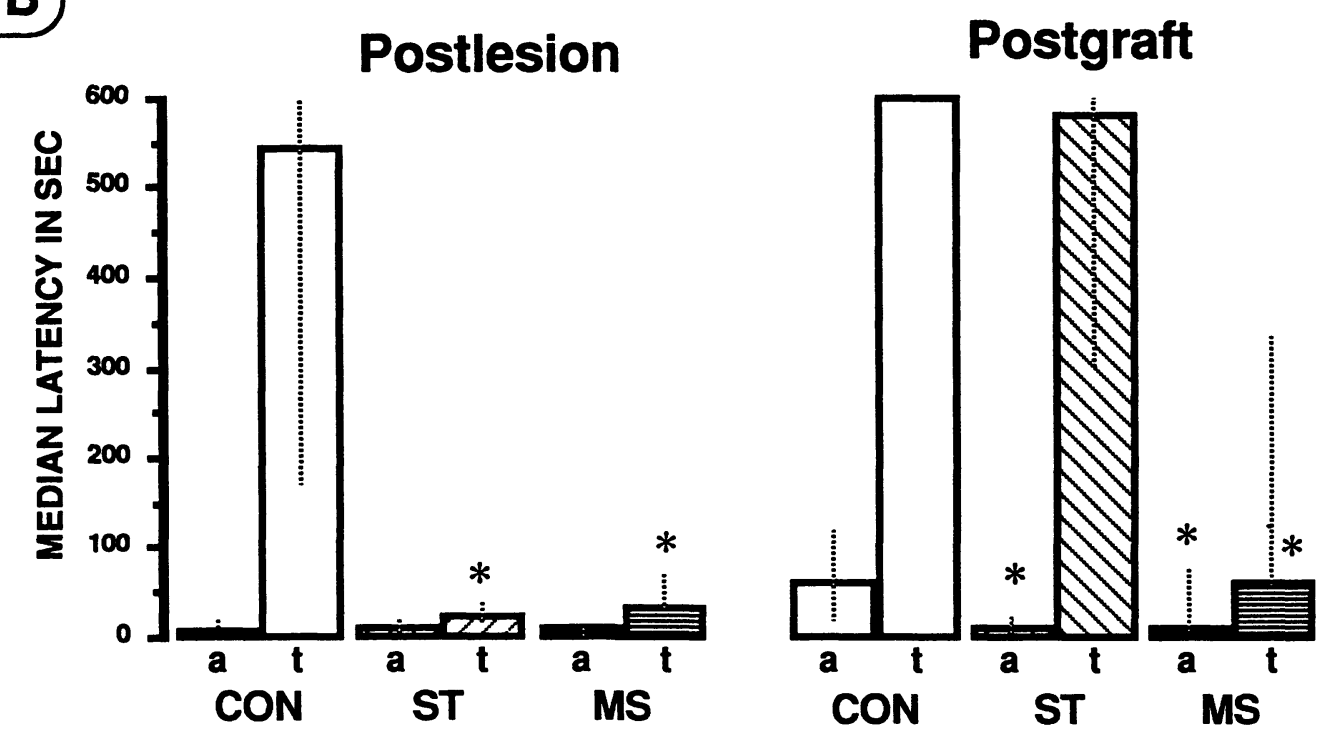

Fig. 1: Post-lesion and post-graft inhibitory avoidance performance at fifteen (A) and sixty (B) days after transplantation. The first bar of each pair represents the latency for the acquisition (a) session, and the second bar of each pair represents the latency for the test (t) session. Control (CON) and experimental groups: striatal (ST), mesencephalic (MS). ${ }^{*} \mathrm{p}<0.01$ (Mann-Whitney U-test) as compared with the control groups. Dotted lines indicate interquatile range. 
the CON-15 group showed a significantly higher latency compared to the ST-15 and MS-15 groups $(p<0.05)$. During the test day the analyses revealed significant differences among groups $(\mathrm{p}<0.01)$. The CON-15 group and the animals that received the striatal grafts (ST-15) showed the highest latency and there were no statistical differences between them, indicating that those groups showed a good acquisition of the task. The groups receiving mesencephalon (MS-15) still showed impaired learning with significantly lower latencies when compared with the CON-15 and ST-15 groups $(\mathrm{p}<0.05)$

Results from post-lesion and post-graft sessions for sixty day-old grafts are shown in Figure 1B. The analysis for post-lesion acquisition and test sessions showed similar results to those at fifteen days, i.e. in the acquisition session the groups showed similar latencies. During the test session there were significant differences between groups $(p<0.01)$. The lesioned animals showed significantly lower latencies in comparison with the control group $(p<0.01)$. Similarly, the analysis for the acquisition at 60 days post-graft revealed that there were significant differences among groups $(p<0.01)$. The CON-60 group showed significantly higher latencies as compared with the ST-60 and MS-60. During the test session the CON-60 and ST-60 groups showed the highest latencies, and there were no significant differences between them. The MS-60 group showed impaired learning with significantly lower latencies when compared with CON-60 and ST-60 groups $(\mathrm{p}<0.05)$.

The results of the determination of ChAT and GAD activities and dopamine content are shown in Figure 2. The ANOVA for ChAT activity revealed significant differences among groups $(\mathrm{F} 2,46=4.993$, $p<0.01$, for 15 days post-graft; $F 2,32=14.865$ $\mathrm{p}<0.01$ for 60 days post-graft). The ChAT activity in striatal grafts, at either 15 or 60 days, was similar to that of the intact control tissues, whereas that in the mesencephalic grafts was only $22.9 \%$ (for 15 day-old grafts) and $35.2 \%$ (for 60 day-old grafts) as compared with their control groups. In contrast, GAD activity was significantly lower than the control in both striatal and mesencephalic groups $(\mathrm{F} 2,26=2.366 ; \mathrm{p}<0.01$ at 15 day-old post graft).

\section{A Fifteen day old grafts}
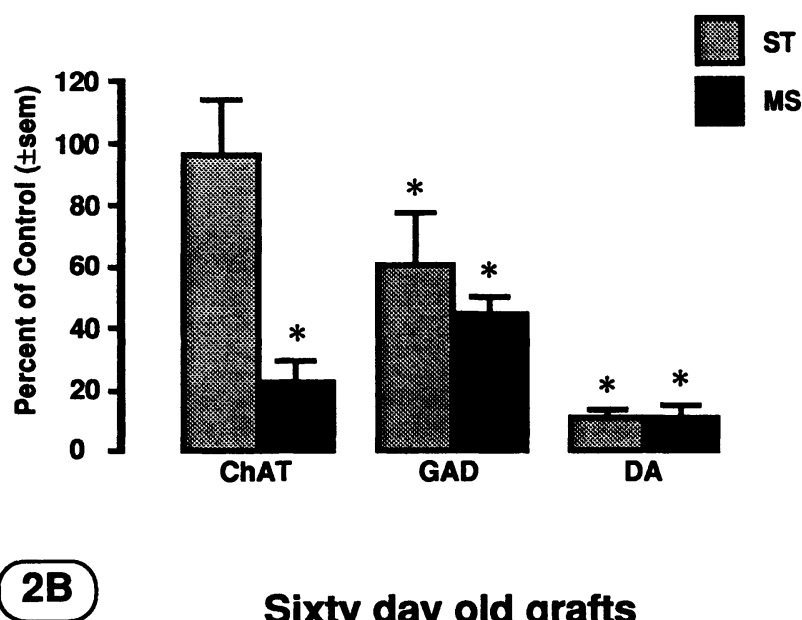

Sixty day old grafts

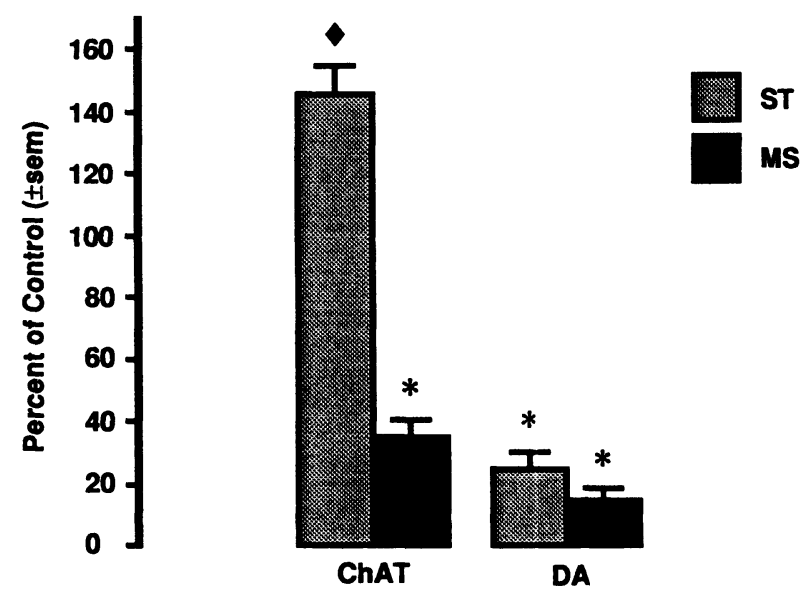

Fig. 2: ChAT and GAD activities and dopamine (DA) content in striatal and mesencephalic grafts as percentages of the control. (A) Results for fifteen days. (B) Results for sixty days. ${ }^{*} p<0.01$ lower than control and $-p<0.01$ higher than control (Fisher test). The absolute control values were for ChAT: CON-15, $47.0 \pm 9 \mathrm{nmol} / \mathrm{mg}$ prot $/ \mathrm{h}$; CON$60,66.8 \pm 17.8 \mathrm{nmol} / \mathrm{mg}$ prot $/ \mathrm{h}$. For GAD activity: $211 \pm 49 \mathrm{nmol} / \mathrm{mg} \mathrm{prot} / \mathrm{h}$. for DA: CON-15, $3.866 \pm 0.8 \mu \mathrm{g} / \mathrm{g}$ wet tissue; CCN-60, $3.5 \pm 0.5 \mu \mathrm{g} / \mathrm{g}$ wet tissue.

A Spearman rank correlation showed that ChAT activity had a significant positive correlation with the post-graft latencies test scores of the inhibitory avoidance task $(\rho=0.644, p<0.001$ for fifteen days; and $\rho=0.720, p<0.01$ for sixty days), whereas no significant correlation was found between the GAD and the test scores ( $\rho=0.174$, for fifteen days). 
Similarly to GAD, the ANOVA for dopamine values (Figure 2) revealed that at both 15 and 60 days post-graft, the striatal and mesencephalic grafts had no differences between them, but both showed significantly lower concentrations when compared with their control groups $(\mathrm{F} 2,19=36.478$, $\mathrm{p}<0.01$ for 15 days grafts; $F 2,45=36.018, \mathrm{p}<0.01$ for 60 days grafts). These values showed no correlation with the test latency scores $(\rho=0.066$, for fifteen days; $\rho=0.111$, for sixty days).

In summary, the present findings show that striatal but not mesencephalic grafts can promote the recovery of the ability to acquire an inhibitory avoidance task. The behavioral recovery can be seen at early stages of graft development and, furthermore, the ChAT activity in these grafts has a positive correlation with the behavioral recovery.

In a previous study $/ 22 /$ we found that striatal, but neither mesencephalic nor cortical grafts, can promote the recovery of an inhibitory avoidance task at 60 days post-graft in striatal lesioned rats. It was also shown that lesioned animals were unable to recover the ability to acquire the same task at 60 days after the lesion, even with two acquisition sessions $/ 22 \%$. Other authors have reported that in rats with an ibotenate-lesioned striatum, striatal and mesencephalic grafts can promote the recovery of a variety of behaviors $/ 11,20,29 /$, such as skilled paw reaching $/ 10,28 /$, spatial alternation learning and $T$ maze $/ 7,16 /$, or motor activity $/ 25,26 /$. In these reports, functional recovery was observed at times over two months post-graft and it is stated that connectivity of the grafts is important for the recovery of functional deficits $/ 5,29 /$. In our model, 15 days after implantation were enough to induce the recovery of the ability to acquire the passive avoidance task. In our view, at this time (15 days) it is improbable that the graft can establish a complete reconnectivity with the host tissue /13/.

Cholinergic neurotransmission has been considered an important system related to learning and memory functions $/ 8 /$. We have recently shown that acetylcholine plays an important role in the recovery of conditioned taste aversion in insular cortex lesioned rats $/ 12 /$. Regarding the striatum, some reports have shown that scopolamine-induced cholinergic blockade of the dorsal area of the striatum induces deficits in the acquisition of inhibitory avoidance $12,23 /$. The present

VOLUME 5, NO. 1, 1994 experiments also suggest a cholinergic involvement in the recovery, since striatal grafts induced recovery of the behavioral task and possessed ChAT activity similar to control tissue, whereas the mesencephalic grafts, having low levels of ChAT activity, did not induce recovery. Thus, a statistically significant correlation of ChAT activity and behavioral recovery was found. It remains to be determined what is the precise role of acetylcholine in the functional recovery induced by fetal striatal grafts.

In contrast, no significant correlation was found for graft GAD activity and dopamine graft content with the behavioral recovery, although this, by no means, indicates that GABA or dopamine are not related to the functional activity of the striatum. In fact, these two neurotransmitters have been related to the striatal graft-promoted recovery of motor activity $/ 15,21,30 /$. Thus, the involvement of other neurotransmitter systems or other factors in the recovery of function cannot be dismissed.

The present findings demonstrate that early recovery of a behavioral function after transplantation can occur, and that this recovery, at least in our model, is correlated with striatal graft ChAT activity.

\section{ACKNOWLEDGEMENTS}

This study was supported by grants DGAPA IN 204689, IN 201893 and CONACyT 0178-N9107. We thank Mr. Juan Carlos López García for his contribution and Mr. Oreste Carbajal for technical assistance.

\section{REFERENCES}

1. Albers RW, Brady RD. The distribution of glutamic acid decarboxylase in the nervous sytem of the Rhesus monkey. J Biol Chem 1959; 234: 926-928.

2. Bermúdez-Rattoni $F$, Mújica-González $M$, PradoAlcalá RA. Is cholinergic activity of the striatum involved in the acquisition of postively-motivated behaviors? Pharmacol Biochem Behav 1986; 24: 715719.

3. Björklund A, Stenevi U. Intracerebral neural implants: neural replacement and reconstruction of damaged circuitries. Ann Rev Neurosci 1984; 7: 279-308.

4. Björklund $A$, Lindvall $O$, Isacson $O$, Brundin $P$, Wictorin K, Strecker RE, Clarke DJ, Dunnett SB. Mechanisms of action of intracerebral neural implants: studies on nigral and striatal grafts to the lesioned striatum. Trends Neurosci 1987; 10: 509516. 
5. Björklund A. Neural transplantation: an experimental tool with clinical possibilities. Trends Neurosci 1991; 14: 319-322.

6. Cassel JC, Kelche C, Majchrzak M, Will BE. Factors influencing structure and function of intracerebral grafts in the mammalian brain: a review. Rest Neur Neurosci 1992; 4: 65-96.

7. Deckel AW, Moran TH, Robinson RG. Behaviroal recovery following kainic acid lesions and fetal implants of the striatum occurs independent of dopaminergic mechanisms. Brain Res 1986; 363: 383385.

8. Decker MW, McGaugh JL. The role of interactions between the cholinergic and other neuromodulatory systems in learning and memory. Synapse 1991; 7: 151-168.

9. Dunnett SB, Isacson O, Sirinathsinghji DJS, Clarke DJ, Björklund A. Striatal grafts in the ibotenic acidlesioned neostriatum: functional studies. In: Gash DM, Sladek JR, eds, Transplantation into the Mammalian CNS, Prog Brain Res. Amsterdam: Elsevier 1988; 39-45.

10. Dunnett SB, Isacson O, Sirinathsinghji DJS, Clarke DJ, Björklund A. Striatal grafts in rats with unilateral neostriatal lesions: recovery from dopamine dependent asymmetry and deficits in skilled paw reaching. Neuroscience 1988; 24: 813-820.

11. Dunnett SB. Functional analysis of neural grafts in the neostriatum. In: Björklund A, Aguayo AJ, Ottosson D, eds, Brain Repair: Wenner-Gren International Symposium Series. London: McMillan 1990; 355-373.

12. Escobar ML, Jiménez N, López-Garcia JC, Tapia R, Bermúdez-Rattoni F. Nerve growth factor with insular cortical grafts induces recovery of learning and restablishes graft choline acetyltransferase activity. J Neur Transplant Plast 1993; 4: 167-172.

13. Fernández-Ruiz J, Escobar ML, Piña AL, Diaz-Cintra S, Cintra-McGlone FL, Bermúdez-Rattoni F. Timedependent recovery of taste aversion learning by fetal brain transplants in gustatory neocortex-lesioned rats. Behav Neur Biol 1991; 55: 179-193.

14. Fonum F. A rapid radiochemical method for the determination of choline acetyltransferase. J Neurochem 1975; 24: 407-409.

15. Horrellou P, Marlier L, Privat A, Mallet J. Behavioral effects of engineering cells that synthesize L-DOPA or dopamine after grafting into the rat neostriatum. Eur J Neurosci 1990; 2: 116-119.

16. Isacson O, Dunnett SB, Björklund A. Graft-induced behavioral recovery in an animal model of Huntington's disease. Proc Natl Acad Sci USA 1986; 83: 2782-2792.

17. López-García JC, Bermúdez-Rattoni $F$, Tapia $R$. Release of acetylcholine, $\gamma$-aminobutyrate, dopamine and glutamate and activity of some related enzymes in rat gustatory neocortex. Brain Res 1990; 523: 100104.
18. López-García JC, Fernández-Ruiz J, BermúdezRattoni F, Tapia R. Correlation between acetylcholine release and recovery of conditioned taste aversion induced by neocortex grafts. Brain Res 1990; 523: 105-110.

19. Lowry O, Rosenbrough N, Farr A, Randall RJ. Protein measurement with the Folin phenol reagent. J Biol Chem 1951; 193: 265-275.

20. Norman AB, Lehman MN, Sanberg PR. Functional effects of fetal striatal transplants. Brain Res Bull 1989; 22: 163-172.

21. Mogenson GJ, Nielsen MA. Evidence that an accumbens to subpallidal GABAergic projection contributes to locomotor activity. Brain Res Bull 1983; 11: 309-314.

22. Piña $\mathrm{AL}$, Ormsby $\mathrm{CE}$, Bermúdez-Rattoni $\mathrm{F}$. Differential recovery of inhibitory avoidance learning by striatal, cortical and mesencephalic fetal grafts. Behav Neur Biol 1994; 61: 196-201.

23. Prado-Alcalá RA. Is cholinergic activity of the caudate nucleus involved in memory? Life Sci 1985; 37: 2135 2142.

24. Sanberg PR, Calderon SF, Garver DL, Norman AB. Brain tissue transplants in an animal model of Huntington's disease. Psycopharmacol Bull 1987; 23: 476-482.

25. Sanberg PR, Henault MA, Deckel AW. Locomotor hyperactivity: effects of multiple striatal transplants in an animal model of Huntington's disease. Pharmac Biochem Behav 1986; Suppl. 25: 297-301.

26. Sanberg PR, Giordano M, Henault MA, Nash DR, Ragozzino ME, Hagenmayer-Hauser SH. Intraparenchimal striatal transplants required for maintenance of behavioral recovery in an animal model of Huntington's disease. J Neural Transpl 1989; 1: 23-31.

27. Taylor RB, Reid R, Kendle KE, Geddes C, Curles PF. Assay procedure for the determination of biogenic amines and their metabolites in rat hypothalamus using ion-pairing reversed-phase high-performance liquid chromatography. J Chromat 1983; 277: 101114.

28. Valousková V, Brachá V, Bures J, Hernández-Mesa N, Marcias-Gonzalez R, Mazurova Y, Nemecek S. Unilateral striatal grafts induce behavioral and electrophysiological asymmetry in rats with bilateral kainate lesions of the caudate nucleus. Behav Neurosci 1990; 104: 671-680.

29. Wictorin K. Anatomy and connectivity of intrastriatal striatal transplants. Prog Neurobiol 1992; 38: 611639.

30. Wolff JA, Fisher LJ, Xu L, Jinnah HA, Langlais PJ, Iuvone M, O'Malley KL, Rosenberg MB, Shimohama S, Friedmann T, Gage FH. Grafting fibroblasts genetically modified to produce L-DOPA in a rat model of Parkinson's disease. Proc Natl Acad Sci USA 1989; 86: 9011-9014. 

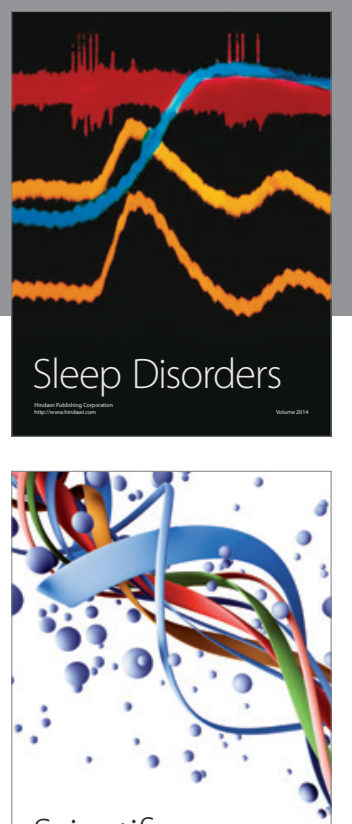

Scientifica
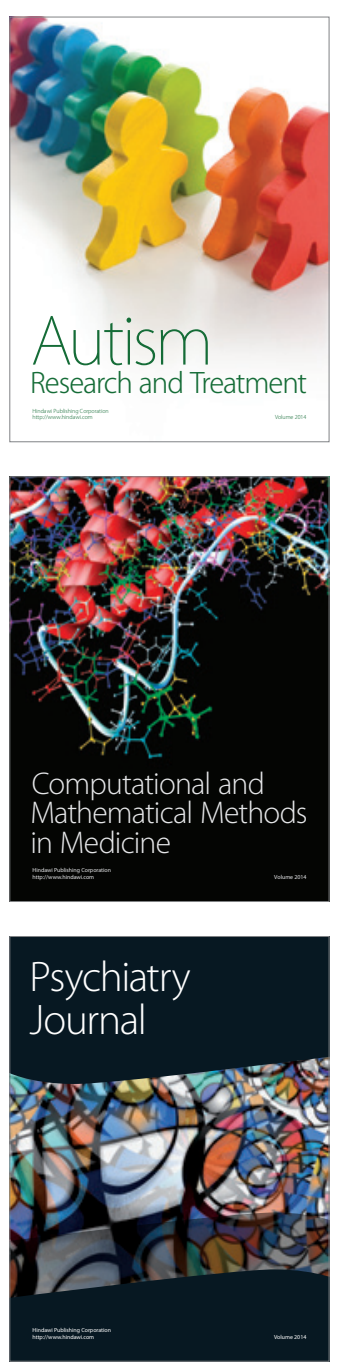
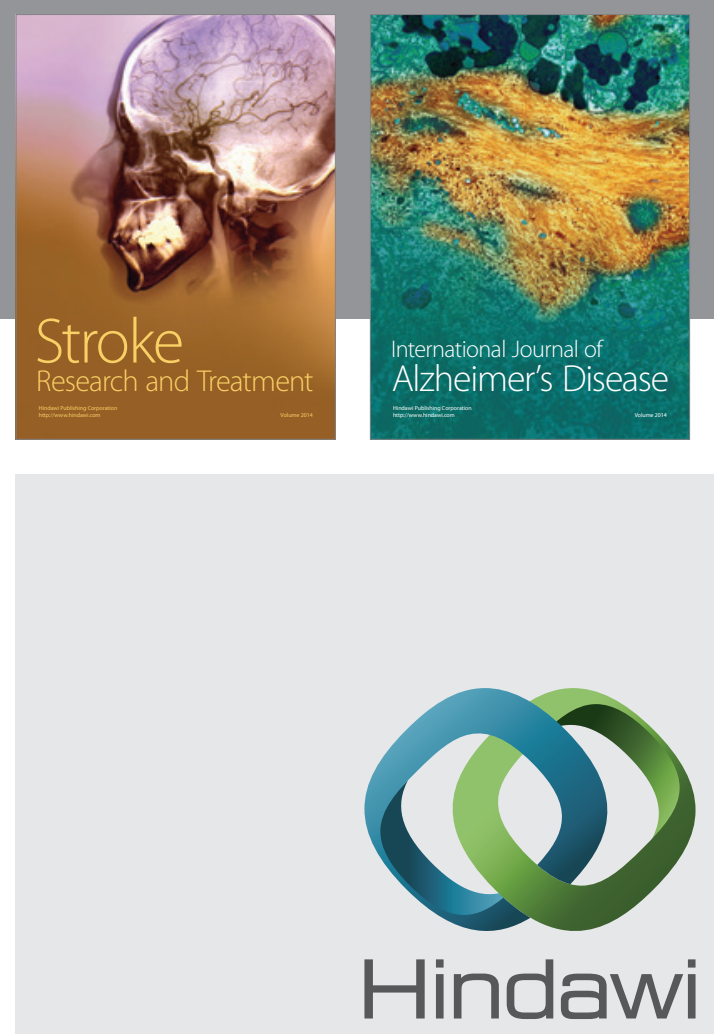

Submit your manuscripts at

http://www.hindawi.com
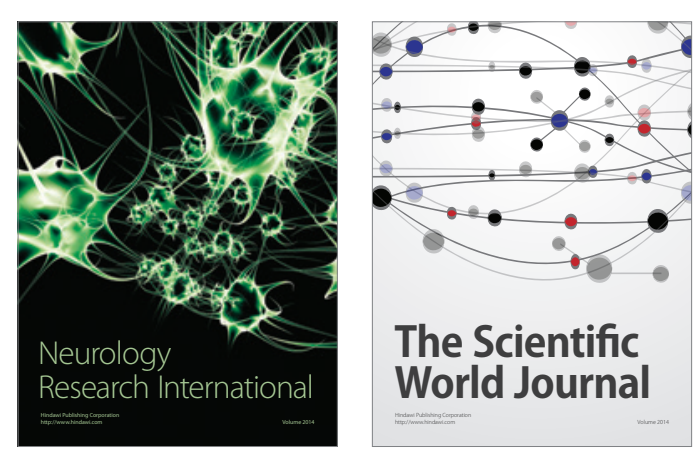

The Scientific World Journal

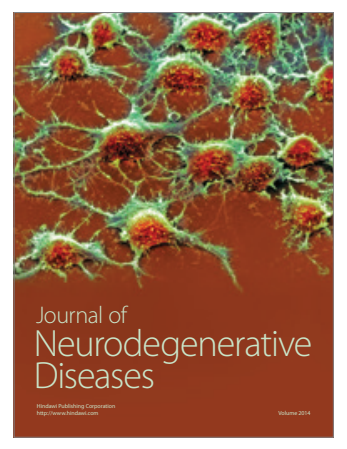

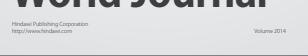

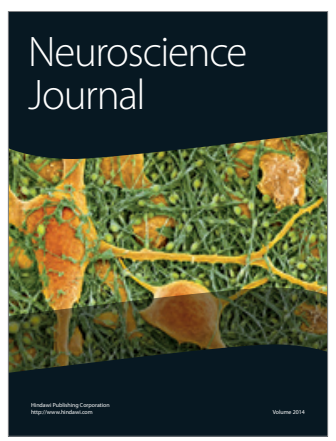

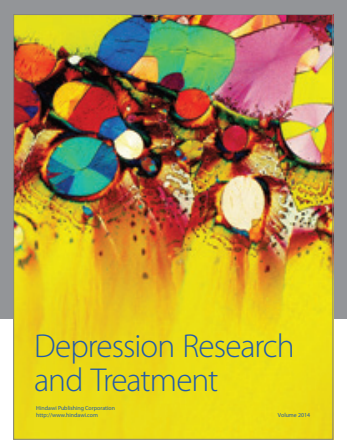
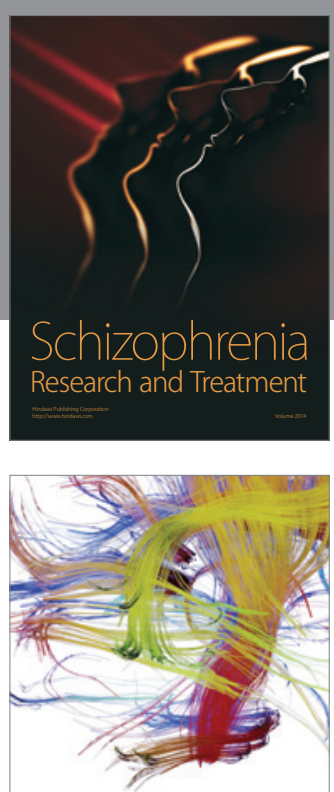

Brain Science

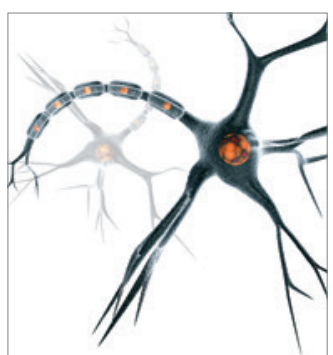

Neural Plasticity
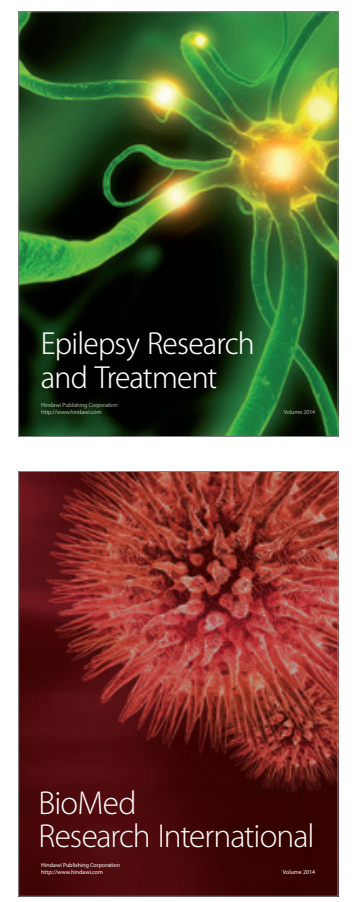

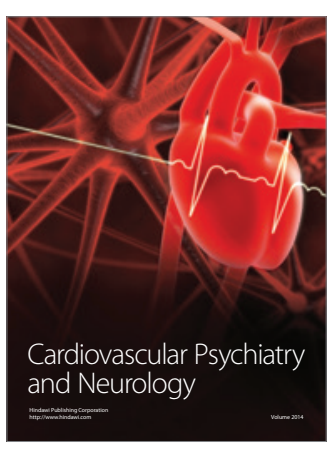

Parkinson's

Disease
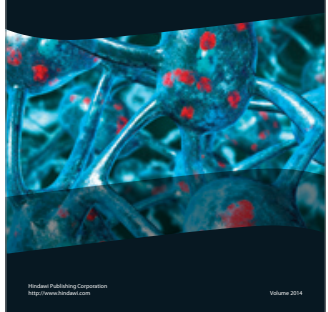